\title{
THIẾT KẾ VÀ THỰC HIỆN CÁC HỌC PHẦN CHUYÊN NGÀNH KỸ THUẬT ĐIỆN, ĐIỆN TỬ THEO CDIO ĐÁP ÚNG YÊU CÂU THỤC TẾ TẠI TRƯỜNG ĐẠI HỌC CÔNG NGHỆ ĐỒNG NAI
}

\author{
Văn Bá Tài ${ }^{(*)}$, Lê Thanh Lành ${ }^{(* *)}$ \\ (*) Thạc sĩ. Trường Đại học Công nghệ Đồng Nai. Email: vanbatai@ dntu.edu.vn. \\ (**) Tiến sĩ. Truờng Đại học Công nghệ Đồng Nai. Email: lethanhlanh@dntu.edu.vn.
}

DOI: $10.37550 /$ tdmu.CFR/2021.01.106

\section{Tóm tắt}

Trong chwơng trình đào tạo chuyên ngành Kỹ thuật Điện -, Điện tủ tại Truờng Đại họ Công nghệ Đồng Nai, cũng nhu tại các trường đại học kỹ thuật khác, các hoc phần chuyên ngành đóng vai trò quan trọng trong viẹc hình thành, phát triển kiến thức, kỹ năng, cả về thái độ và đạo đức nghề nghiệp cho sinh viện sau khi ra trương. Tuy nhiên. việc đào tạo theo phuơng pháp, mô hình chuyển giao kiến thức không còn phù hợp với thời đại công nghiệp 4.0 mà dần chuyển sang mô hình đào tạo chú trọng đến phát triển các kỹ năng nghề nghiệp theo định huớng CDIO. Bộ môn Công nghệ Kỹ thuật Điện -, Điện tư, Khoa Công nghệ ngay tù năm 1, năm 2, trong nhũng môn cơ sở ngành đã tích cưc cho sinh viên đi kiến tập, tham quan nhà máy nhằm quan sát, hình thành các ý twởng. Các học phần chuyên ngành ở năm 3, năm 4 được thiết kế và thưc thiện theo dụ án-CDIO. Việc triển khai các học phần này theo CDIO, qua các bước: (1) đề xuất hoạc chọn lựa các ý tưởng, (2) thiết

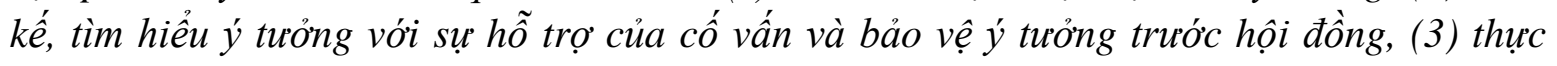
hiện ý tương đó. Trong bài báo này, chúng tôi trình bày phuơng pháp học tập cho các nhóm của sinh viên để thực hiện việc thiết kế, thi công giải pháp cải tiến kỹ thuật theo yêu cầu đổi mới công nghệ và có tác động tích cưc đến xã hội. Phuơng pháp luận và một số kết quả thực hiện của phuoong pháp cho thấy sự phù hợp của phuơng pháp CDIO.

Tù̀ khóa: CDIO, chương trình đào tạo, chuẩn đầu ra, đào tào theo nhu cầu thưc tế.

\section{1. Đặt vấn đề}

Nhằm đáp ứng yêu cầu đào tạo trong thời đại công nghiệp 4.0, Trường Đại học Công nghệ Đồng Nai nói chung, Bộ môn Kỹ thuật Điện - Điện tử nói riêng đã quyết liệt trong việc thay đổi, chỉnh sửa chương trình đào tạo, đề cương chi tiết của các học phần theo CDIO. Việc thiết kế, xây dựng chương trình đào tạo được sắp xếp phù hợp giữa các môn cơ sở ngành và các môn chuyên ngành. Nghĩa là, các môn cơ sở ngành được sắp xếp đào tạo ở năm 1 , năm 2 , kết hợp với các chương trình kiến tập - đi thực tế doanh nghiệp. Trong giai đoạn này, sinh viên vừa được tích lũy kiến thức vừa hình thành những ý tưởng thông qua 
những chuyến đi thực tế. Trong năm 3 , năm 4 , sinh viện tiếp tục được đào tạo những kiến thức chuyên ngành đồng thời có thể hiện thực hóa ý tưởng đề tạo ra các sản phẩm kỹ thuật sát với yêu cầu thực tế.

Như vậy, chương trình đào tạo ngành Kỹ thuật Điện - Điện tử 2018 với sư thiết kế và thực hiện theo định hướng CDIO giúp nâng cao được chất lượng đào tạo, đặc biệt là đáp ứng được yêu cầu đào tạo sát với thực tế doanh nghiệp. Đây cũng là một trong hai chương trình đào tạo của trường Đại học Công nghệ Đồng Nai được Trung tâm Kiểm định Đại học Quốc gia Hà Nội đánh giá đạt chuẩn.

\section{Thiết kế, xây dựng và thực hiện các học phần chuyên ngành Kỹ thuật Điện - Điện tử theo CDIO}

Trong chương trình đào tạo chuyên ngành Kỹ thuật Điện, Điện tử năm 2016 và chỉnh sửa vào năm 2018, các học phần chuyên ngành bao gồm các học phần bắt buộc và các học phần tự chọn, đặc biệt là các học phần Đồ án (Đồ án học phần 1, 2, Đồ án tốt nghiệp ). Việc thiết kế, xây dựng, và thực hiện các học phần này theo CDIO đã được định hướng từ những năm 1,2 ).

\subsection{Quan sát và hình thành ý tưởng}

Ngay từ những năm 1,2 của chương trình đào tạo, việc cho sinh viên đi kiến tập tại các doanh nghiệp được thực hiện gần như là bắt buộc. Từ những chuyến đi thực tế này, sinh viên có cơ hội quan sát và hình thành những ý tưởng kỹ thuật.
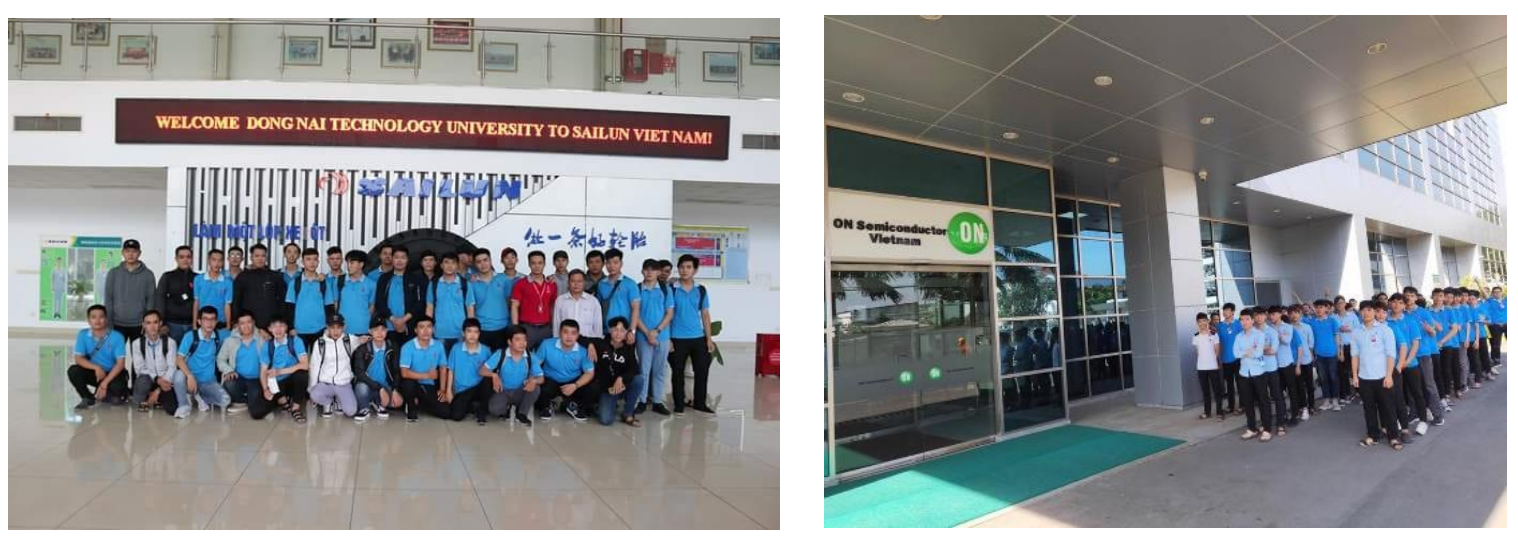

Hinh 1: Sinh viên DNTU đi thực tế doanh nghiệp để hình thành ý tuởng

\subsection{Thiết kế, thục hiện, tạo ra sản phẩm kỹ thuật}

Xuất phát từ những ý tưởng của sinh viên được hình thành trong những chuyến đi thực tế, hoặc các ý tưởng thu thập từ cựu sinh viên, đề xuất từ các giảng viên đã được chọn lọc, sinh viên được chia nhóm và thực hiện.

Quá trình thực hiện các dự án được tiến hành theo trình tự C-D-I-O (Hình thành ý tưởng - Thiết kế - Thực hiện - Vận hành). 


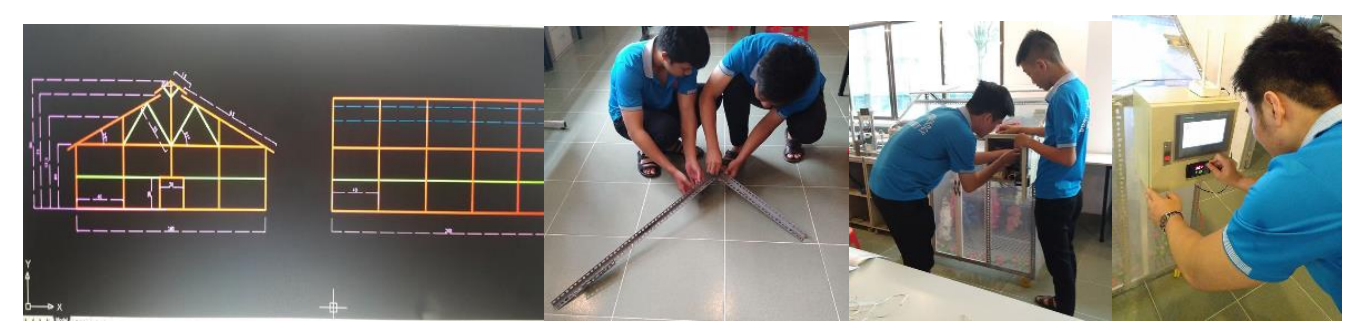

Hình 2: Quá trình sinh viên thục hiện dụ án

Trong suốt quá trình dự án, các nhóm sinh viên phải thường xuyên thảo luận với nhau, tham vấn, hỗ trợ từ các cựu sinh viên, và đặc biệt là giảng viên hướng dẫn. Như vậy, để hoàn thiện dự án, các nhóm sinh viện phải thường xuyên Quan sát, Đánh giá, Thiết kế, Thực hiện để tạo ra một sản phẩm kỹ thuật hoàn chỉnh.

Các dự án sau khi hoàn chỉnh sẽ được đánh giá bởi hội đồng khoa học bộ môn. Những sản phẩm kỹ thuật tốt sẽ được chọn lựa tham gia các hội thi sáng tạo kỹ thuật cấp trường, cấp tỉnh.
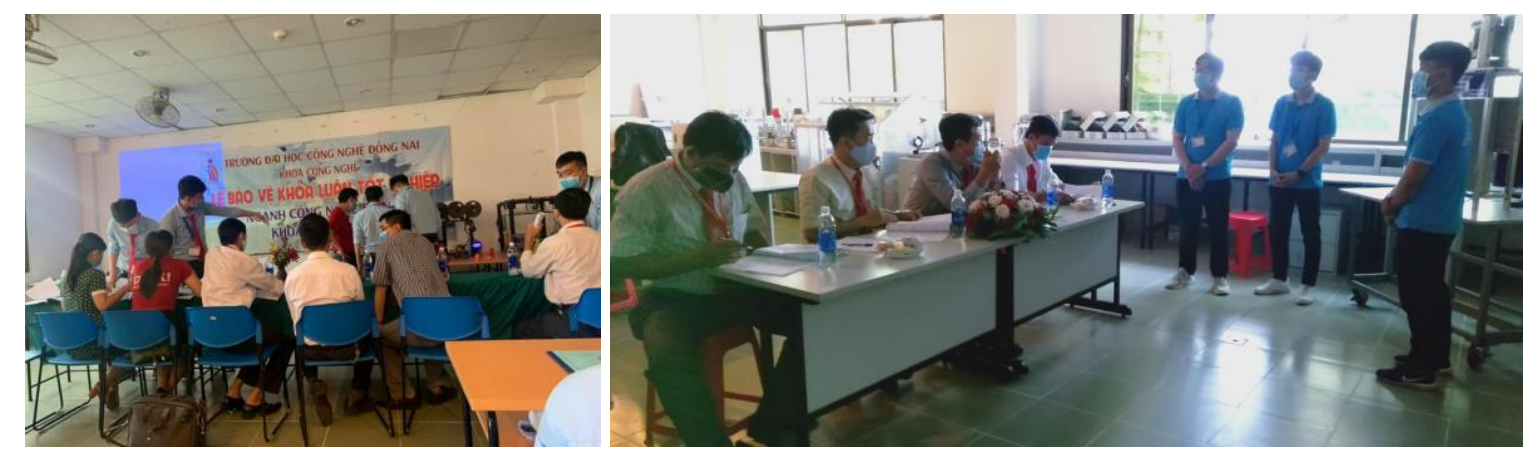

Hình 3: Đánh giá các dụ án - sản phẩm kỹ thuật sinh viên

\section{Những khó khăn và thách thức}

Trong quá trình thiết kế, xây dựng, và thực hiện các học phần chuyên ngành Kỹ thuật Điện - Điện tử theo CDIO, bộ môn được sự hỗ trợ, đóng góp ý kiến từ các chuyên gia, lãnh đạo nhà trường, cũng như lãnh đạo khoa. Tuy nhiên cũng gặp phải những khó khăn và thách thức sau:

- Kinh phí mua trang thiết bị để thực hiện dự án.

- Các ý tưởng đề xuất từ sinh viên còn ít và chưa thực tiễn.

- Để hoàn thành dự án, các nhóm sinh viên phải tự học và cập nhật những kiến thức không thuộc chuyên ngành đào tạo.

- Sự hỗ trợ và đóng góp ý kiến của các chuyên gia, cựu sinh viên còn hạn chế về thời gian.

\section{Kết luận và những đề xuất}

Qua thời thực hiện áp dụng CDIO cho các học phần chuyên ngành Kỹ thuật Điện, Điện tử tại Trường Đại học Công nghệ Đồng Nai, chất lượng đào tạo đã được nâng lên rõ 
rệt. Điều này được thể hiện trong số lượng và chất lượng của sinh viện đã được tạo ra. Các kỹ năng tư duy sáng tạo, kỹ năng làm việc nhóm, đặc biệt là kỹ năng thuyết trình của sinh viên đã được chú trọng đào tạo trong suốt quá trình thực hiện các dự án. Việc định hướng hình thành các ý tưởng kỹ thuật từ những chuyến đi thực tế doanh nghiệp đã giúp sinh viên tạo ra các sản phẩm kỹ thuật có tính ứng dụng hơn. Tuy nhiên, với những khó khăn và thách thức trong quá trình thiết kế, xây dựng, và thực hiện các học phần chuyên ngành Kỹ thuật Điện - Điện tử theo CDIO, nhóm tác giả xin được đưa ra các đề xuất sau:

- Tạo sự gắn kết hơn nữa giữa nhà trường và doanh nghiệp. Sinh viên sẽ được tham gia vào các dự án kỹ thuật của doanh nghiệp.

- Thêm nhiều hơn nữa các môn học tự chọn, hoặc các chuyên đề kỹ thuật theo chuyên ngành, cũng có thể không theo chuyên ngành cho sinh viên chọn lựa.

- Các giảng viên cần nỗ lực hơn nữa và đồng hành cùng sự phát triển giáo dựa, đào tạo trong thời đại công nghiệp 4.0.

\section{Tài liệu tham khảo}

[1] JT Hernández, MC Ramírez - Fostering Design Communication Skills: A CDIO Inspired Innovation Engineering Course. Website http://cdio.org

[2] Gilbuena, D.M., Sherrett, B.U.,Gummer, e.s., Champagne, A.B. \&Korest (20156. Feedback on professional skills as enculturation into communities of practice. Journal of Engineering Education, 104 (1), 7-34. doi 10.1002/jee.20061

[3] Đoàn Thị Minh Trinh, Nguyễn Hội Nghĩa, "Hướng dẫn thiết kế và phát triển chương trình đào tạo đáp ứng chuẩn đầu ra”. NXB Đại học Quốc gia TP.HCM, 2014.

[4] Hồ Tấn Nhựt, Đoàn Thị Minh Trinh (biên dịch), Cải cách và xây dựng chương trình đào tạo kỹ thuật theo phương pháp tiếp cận CDIO, NXB Đại học Quốc gia TP.HCM, 2009.

[5] https://tdmu.edu.vn/cdio

[6] www.cdio.org 